Nig. J. Biotech. Vol. 37(2): 113-125 (Dec. 2020)

ISSN: 01891731

Available online at

http://www.ajol.info/index.php/njb/index

and www.biotechsocietynigeria.org

DOI: https://dx.doi.org/10.4314/njb.v37i2.11

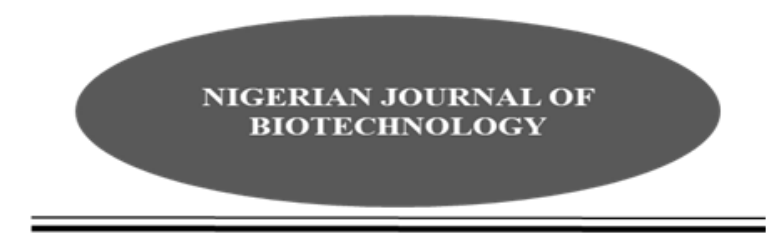

\title{
Methods for the Phenotypic Detection of Extended Spectrum Beta Lactamase (ESBL)-Producing Bacteria
}

\author{
Salihu, M.K1 ${ }^{1}$, Yarima, A $^{2}$ and Atta ${ }^{3}$, H.I \\ ${ }^{1}$ Department of Microbiology, Federal University Dutsin-ma, Katsina State, Nigeria. \\ 2Department of Plant Science, Bio resource Development Centre Michika, National Biotechnology \\ Development Agency \\ ${ }^{3}$ Department of Microbiology, Ahmadu Bello University, Zaria, Kaduna State, Nigeria
}

\begin{abstract}
Extended Spectrum Beta Lactamases (ESBLs) are first reported in Klebsiella pneumonia in 1983. These enzymes possess the ability to inactivate susceptible $\beta$-lactam antibiotics i.e. penicillins, first, second and third generation cephalosporins and aztreonam, but not cephamycins and carbapenems . Their mode of action is by hydrolyzing the $\beta$-lactam ring. Even before the first $\beta$-lactam antibiotic (penicillin) was developed, resistance to $\beta$-lactam antibiotics was observed. ESBL genes are plasmids- and transposons- mediated, as such, can be spread easily to other species of bacteria. Resistance of ESBL- producing bacteria to the $\beta$-lactam antibiotics is a continuing cause of public health problems, it is increasingly being observed in community and nosocomial acquired infections. Detection and identification of these ESBLs in the laboratory is of prime importance for the selection of appropriate antibiotics to be used in the treatment of infections caused by ESBL- producing bacteria. The aim of this review is to explain in detail , several phenotypic methods used in the detection and confirmation of extended spectrum $\beta$ lactamases.
\end{abstract}

Keywords: Antibiotic resistance, ESBL, bacteria, phenotypic method

*Corresponding author's email;emkayikara@gmail.com

\section{Introduction}

Beta lactam antibiotics are a class of broad spectrum antibiotics that contain a $\beta$-lactam ring in their core molecular structures (Maria, 2013). They are among the most commonly prescribed antimicrobial agents worldwide to treat bacterial infections (Bradford, 2001; Shaikh et al., 2015). Prestinaci et. al., (2015), reported that their costeffectiveness, ease of use and tolerability make them the most widely used antibacterial agents. The effectiveness of these antibiotics has been decreased due to the development of resistant mechanisms in certain bacterial species (WHO, 2014) as a result of indiscriminate consumptions. Production of $\beta$-lactamases remains the major mechanism employed by bacteria to resist the effects of antimicrobial agents used against them (Ximin and Jun, 2013) . The continuous exposure of bacterial strains to multitude of $\beta$-lactam antibiotics has induced the dynamic and incessant production and mutation of $\beta$ lactamases in these bacteria, thereby expanding their activity against the newly developed $\beta$ lactam antibiotics (Shaikh et. al., 2015) . This class of enzymes that can break down these newer antibiotics are termed as ExtendedSpectrum Beta Lactamases (ESBLs) (Paterson and Bonomo, 2005; Pitout and Laupland, 2008; 
Shaikh et. al., 2015). Extended Spectrum Beta Lactamases (ESBLs) are enzymes that mediate resistance to broad spectrum of $\beta$-lactam antibiotics such as penicillins, third generation cephalosporins (e.g. ceftazidime, cefotaxime, and ceftriaxone) and aztreonam, but not to cephamycins (cefoxitin and cefotetan) and carbapenems (Bonnet, 2004; Al-Muharrmi et. al., 2008; Shaikhet. al., 2015) but are being inhibited by beta lactamase inhibitors like clavulanic acid (Al-Muharrmi et. al., 2008).

The ability of bacteria to produce enzymes that destroy the B-lactam antibiotics began even before penicillin was developed (Abrahan and Chain, 1940). The first $\beta$-lactamase was identified in an isolate of Escherichia coli in 1940 (Abrahan and Chain, 1940; Turner, 2005; Gupta, 2007). Although $\beta$-lactamases are estimated to have existed for the past 2 billion years, their evolution and spread have been highly correlated to the anthropogenic development and prolificacy of $\beta$-lactam antibiotics during the past 60 years (Lachmayr et.al., 2009). Therefore, their detection is a major challenge for the clinical microbiologist because they may appear susceptible to certain B-lactam antimicrobial agents during in vitro studies. This could result in treatment failure (Linscott and Brown, 2005) which may lead to high rates of morbidity and mortality in infectious diseases caused by the bacteria producing these enzymes (Kang et. al., 2004). Therefore, the detection and identificatio $\mathrm{n}$ of ESBL-producing bacteria and the knowledge of their resistance are of paramount importance in selecting appropriate antimicrobia Is to be used in the treatment of infections caused by MDR bacteria, thereby reducing the spread of antibiotics resistant bacteria (ARB). AmpC $\beta$-lactamases belong to the Ambler class $C$ and once expressed at high levels confer resistance to many B-lactam antimicrobials, excluding the fourth generation cephalosporins and carbapenems (Deshpade et al., 2006). Unlike ESBLs, these enzymes are not inhibited by commercial $\beta$-lactamase inhibitors (clavunic acid, sulbactam or tazobactam), however, different types of inhibitors, such as boronic acid and cloxacillin have shown good inhibition (Pitout et. al., 2010).

This review aims at explaining in detail, several phenotypic methods used in the detection of extended spectrum $\beta$-lactamases. Numerous detection methods of ESBL have been proposed based on clinical microbiology techniques, these techniques include preliminary screening for ESBL production followed by confirmatory tests. The screening is usually done by disk diffusion techniques, while the phenotypic confirmatory methods rely mainly on the action of beta lactamase inhibitors such as clavulanic acid and tazobactam to increase the zone of inhibition. The various methods that will be reviewed in this study include Double Disc Synergy, Three dimensional, Vitek system, Disk combination, ESBL Chrom Agar, Broth Micro dilution, Nordmann/Dortet/Poirel (NDP) test, and E-test.

\section{ESBL Detection Methods}

Initial Screening Test for ESBL Production

The Clinical and Laboratories Standard Institute (CLSI) as well as European Committee on Antimicrobial Susceptibility testing (EUCAST) recommended a two-step phenotypic approach in detecting ESBL production followed by confirmatory tests. The initial screening may be carried out by broth microdilution or disk diffusion method while the confirmatory test mainly relies on the action of beta lactamase inhibitors to enhance the zone of inhibition (EUCAST, 2012; Yarima et. al., 2019).

\section{Broth Microdilution}

This test has been recommended by both CLSI and EUCAST in screening of ESBL production. In this test, a concentration of $4 \mu \mathrm{g} /$ $\mathrm{mL}$ of Cefpodoxime or $1 \mu \mathrm{g} / \mathrm{mL}$ of Ceftazidime, Aztreonam, Cefotaxime or Ceftriaxone are tested against the test bacteria. After incubation at $37^{\circ} \mathrm{C}$ for 16 hours. Growth at or above the screening concentrations preliminarily indicates possible ESBL production (i.e. for Escherichia coli, Klebsiella pneumoniae, and Klebsiella. oxytoca, MIC $\geq 8 \mu \mathrm{g} / \mathrm{mL}$ for cefpodoxime or MIC $\geq 2 \mu \mathrm{g} / \mathrm{mL}$ for ceftazidime, aztreonam, ce fotaxime, or ceftriaxone; and for $P$. mirabilis, MIC $\geq 2 \mu \mathrm{g} / \mathrm{mL}$ for cefpodoxime, ceftazidime, or cefotaxime). It is recommended that using more than one antimicrobial agent in screening for 
ESBL production improves the sensitivity of the detection method.

\section{Disk Diffusion Method}

Disk diffusion method detects reduced suscepti bility to two or more indicator antibiotics

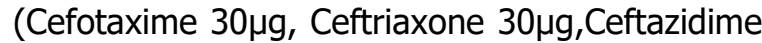

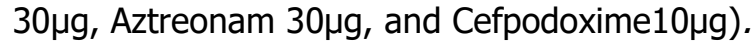
Once an ESBL producer is suspected, it is then confirmed by standardized methods (EUCAST, 2012).

A suspension of the test isolates as well as the standard strains is made using a loopful of its colony in normal saline to achieve a cell turbidity equivalent to the 0.5 McFarland turbidity $1.5 \times 10^{8} \mathrm{CFU} / \mathrm{mL}$. Then inoculums are aseptically streaked on to the surface of MullerHinton agar media using a wire loop. The antibiotic discs are aseptically placed on the surface of Muller Hinton agar using sterile forceps, leaving $15 \mathrm{~mm}$ away from the edge of the Petri dish, the disks were separated from each other by a distance not less than $20 \mathrm{~mm}$ to avoid overlapping zones of inhibition. The inoculated media are then incubated at $37^{\circ} \mathrm{C}$ for 16 hours. Zones of inhibition around the antibiotic disks are measured to the nearest $\mathrm{mm}$ and can be compared with the reference strains of E. coli (ATCC25922) and K. pneumonia (ATCC-700603) as negative and positive controls respectively (CLSI, 2015)

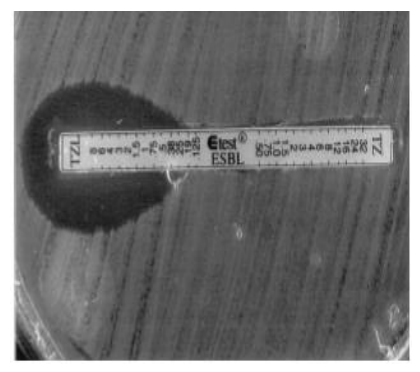

\section{ESBL Confirmation Methods}

\section{E-test Strip (Epsilon test)}

The principle behind the ESBL E-test strip is dilution and diffusion. The ESBL E-test strip is a thin plastic, non-porous strip with dimensions $60 \mathrm{~mm}$ by $5 \mathrm{~mm}$, and bearing two shorter gradients aligned in opposite directions on the same strip (Nitin et. al., 2014), The strip is two sided containing a gradient of one of the Oxyiminocephalosporins (e.g. Ceftazidime alone) on one end and a gradient of Cephalosporin + Clavulanic acid (e.g. Ceftazidime plus clavulanate) on the other (Nitin et. al., 2014, Rahman et. al., 2014). The strip is inoculated on a surface of the agar plate and incubated overnight at $37^{\circ} \mathrm{C}$. After incubation, any reduction of $>3 \log 2$ (doubling) dilution is considered as positive (Figure 1) (Vercauteren et al., 1997; Rahman, et. al., 2014). Numerous reports of ESBLs have been confirmed by the use of E-test from different parts of the world including but not limited to Kaur and Aggarwal, 2013; Rahman et. al., 2014; Singh and Lokhendro 2014;Prabha et. al., 2016 .

This method is sensitive, convenient and easy to use, but it is sometimes difficult to read the test when the minimum inhibition concentration (MIC)s of ceftazidime is low because the clavulanate sometimes diffuses over to the side that contains ceftazidime alone (Rahman, 2014).

Figure1: E-test showing enhance zone of inhibition towards cephalosporin plus clavulanic acid (Source: Vercauteren et. al.,1997).

\section{Combination Disk Test (CDT)}

In this test, a disk containing cephalosporin alone (cefotaxime $30 \mu \mathrm{g}$, or ceftazidime $30 \mu \mathrm{g}$ ) is placed in opposite direction to a disk containing cephalosporin plus clavulanic acid $(20 / 10 \mu \mathrm{g})$ with a distance of $15 \mathrm{~mm}$ apart on Muller Hinton agar medium (Khosravi et. al.,2013;CLSI,
2014; Anand et. al., 2016; Lohani et. al., 2019). The inoculated media are then incubated at $37^{\circ} \mathrm{C}$ for 18-24 hours. After incubation, zones of growth inhibition are measured to the nearest $\mathrm{mm}$, a difference of $>5 \mathrm{~mm}$ for a disk containing cephalosporin plus clavulanic acid compared to a disk containing cephalosporin alone is considered positive as shown in figure 2 (Naseer et. al., 
2007; EUCAST, 2012; Anand et. al., 2016; Shiferaw et. al., 2019;). Shiferaw et. al., (2019) reported that combination disc test is better than double disc synergy test in detecting ESBLs. This method was found to detect ESBL producing Klebsiella with $100 \%$ sensitivity and specificity and was validated with both BSAC and NCCLS methods Carter et al., (2000) as reported by

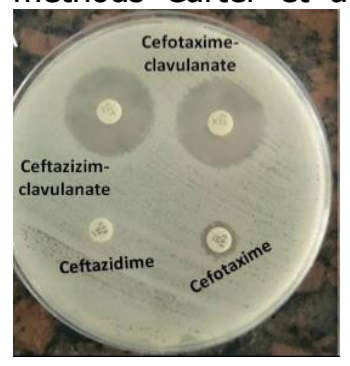

Livermore and Brown, (2001). Combination disc test is a simple and cost effective method of detecting ESBLs (Jabeen et al., 2003). Several studies (Livermore and Brown, 2001; Giriyapur et. al., 2011;EUCAST, 2012; SinghandLokhendro 2014) recommended that the combination disc test be used to confirm ESBL production.

Figure 2: Zone of inhibition around disk with clavulanic acid and disk without clavulanic acid (Source: Mahmoud et. al., 2016).

\section{ESBL Chrom Agar}

This test, offers a rapid screening method for the detection of ESBL producing Gram negative bacteria. The test organisms are inoculated on to a CHROMagar using spread plate technique of direct streaking, and then incubated at $37^{\circ} \mathrm{C}$ for 18-24 hours. Colonies of ESBL producers develop species-specific colors as represented on Table 1 and Figure 3 (Hornsey et. al., 2013; Hassan and Abdalhamid 2014; Prabha et. al., 2016). The advantage of this method is that it is rapid, sensitive and specific ; it also inhibits the growth of other bacteria, including most of those carrying AmpC type resistance (Prabha et. al.,2016). Studies from Uyanga et al., 2019 and Prabha et. al., 2016 reported that ESBL CHROM agar test can be used to confirm ESBL production.

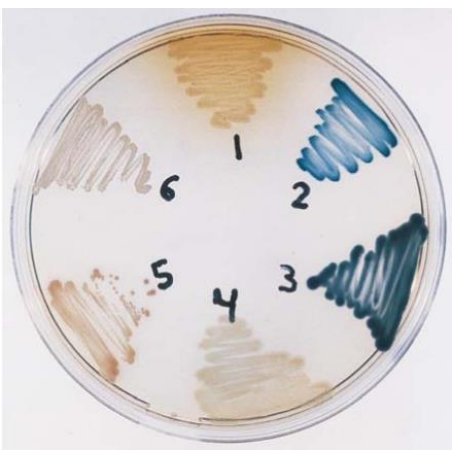

Figure 3: Species-specific colours developed by microorganisms on CHROM agar

Labelled: 1 represent $P$. mirabilis; 2, E. faecalis; 3, K. pneumoniae; 4, P. aeruginosa; 5, E. coli; 6, S. aureus (Samra, et. al., 1998).

Table 1: Differential colours of the various ESBL- producing bacterial genera on Chrom agar.

\begin{tabular}{|l|l|l|}
\hline S/ No & Microorganism & Appearance of the colony \\
\hline 1 & Proteus mirabilis & Brown halo \\
\hline 2 & Escherichia coli & Dark pink to reddish \\
\hline 3 & Klebsiella pneumonia & Mucoid, ${ }^{`}$ Metallic blue \\
\hline
\end{tabular}




\begin{tabular}{|l|l|l|}
\hline 4 & Enterobacter aerogenes & Metallic blue \\
\hline 5 & Citrobacter freundii & Metallic blue \\
\hline 6 & Acinetobacter $s p$ & Cream, Nontransparent, \\
\hline 7 & Pseudomonas aeruginosa & Translucent, yellow serrated edges \\
\hline 8 & Stenotrophomonas & Colourless \\
\hline 9 & Morganellamorganii & Clear diffusible beige on beige background \\
\hline 10 & Torulopsis glabrata & Creamy, very small, indistinct \\
\hline 11 & Enterococcus faecalis. & Dry, turquoise \\
\hline 12 & S. saprophyticus & Pink, Opaque \\
\hline 13 & Staphylococcus aureus & Opaque, white to yellowish \\
\hline 14 & Candidaalbicans & Creamy, wet convex \\
\hline 15 & Pseudomonas aeruginosa. & Transparent, yellow serrated edges, diffuse \\
\hline 16 & Streptococcus $s p$ & Small, translucent; diffuse light blue within agar \\
\hline 17 & Corynebacterium $s p$ & Colorless, small, undifferentiated \\
\hline 18 & Lactobacillus $s p$. & Scanty, light blue within agar \\
\hline
\end{tabular}

Legend; 'Slight pink halo around the periphery after 24 to 36 hours.

yStrong purple-pink halo (diffuse) after 24 to 36 hours.

${ }^{2}$ Green after 24 to 36 hours.

(Source: Samra, et al., 1998;Prabha et. al.,2016)

\section{Double Disk Synergy Test (DDST)}

In this assay, an overnight broth culture of the test bacteria corresponding to 0.5 McFarland turbidity standard is aseptically streaked onto the surface of Mueller-Hinton medium (Rahman et. al., 2014). A susceptibility disk containing amoxicillin plus clavulanate $(20 / 10 \mu \mathrm{g})$ is aseptically placed in the center of the plate, and the cephalosporins disks (ceftriaxone, cefpodoxime, cefotaxime, or ceftazidime) are then placed around it at a distance of $15 \mathrm{~mm}$ from the center of the amoxicillin plus clavulanate disk (Farzana et. al., 2013; Yarima et. al., 2019). The inoculated media are then incubated overnight at $37^{\circ} \mathrm{C}$ (Kaviyarasan, et. al.,2018). An increase in the zone of inhibition towards the centrally placed disk will be considered positive for ESBL production (Peter-Getzlaff., 2011; Caurasia et al., 2015) as shown in Figure 4. This test is reliable for the detection of ESBLs provided that the sensitivity disks are placed at the recommended distance (Rahman et. al.,2014). Jabeen et. al., (2003) recommended that ESBL could be detected by the use of double- disk synergy test, as the method is cost effective and simple. Several other studies (Rahman et. al., 2014; Singh and Lokhendro 2014; Chauhan et. al., 2015 Shu'aibu et.al., 2016; Falodun et. al., 2018: Yarima et. al.,2019) also buttressed the finding that DDST can be used to confirm ESBL production.

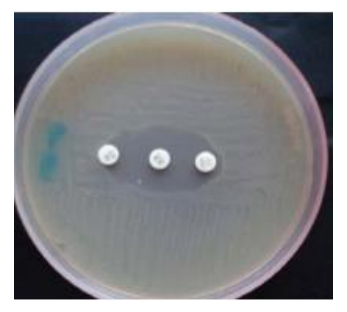

Figure 4: Zone of inhibition toward the centrally placed amoxicillin plus clavulanic acid disc between ceftazidime and cefpodoxime discs as exhibited by an ESBL producing bacterium (Source: Mangaiyarkarasi et. al., 2013)

\section{Three Dimensional Test}

In this method, two types of inocula are prepared, namely; three dimensional inoculum ( $10^{9}$ to $10^{10} \mathrm{CFU} / \mathrm{mL}$ ) and a standard disk diffusion test inoculum (0.5 McFarland turbidity standard) (Nitin et al., 2014). The surface of the Muller-Hinton Agar is inoculated by standard disk diffusion testing method, and a slit is made into the agar using a sterile scalpel blade, then a three dimensional inoculum is pipetted in to the slit. Subsequently, antibiotic disks are placed on the 
surface of the plate at a distance of $3 \mathrm{~mm}$ outside of the inoculated circular slit (Rawat and Nair, 2010; Nitin et. al., 2014). While standard disk diffusion susceptibility test results are measured according to the recommendations of CLSI, the distortion or discontinuity in the expected circular inhibition zone is considered positive for ESBL production (Nitin et. al., 2014). Three dimensional test may be direct or indirect. Indirect modified three dimensional test, as reported by Shaikh et al., (2016) is better than double disc synergy test for ESBL detection. This test is very sensitive in detecting ESBL, but it is technically challenging and more labour intensive than other methods (Thomson and Sanders, 1992). Reports from Rupp and Fey, (2003) and Rahman et.al., (2014) shows that this method is used in detecting ESBL production.

\section{Broth Micro dilution test}

In this assay, a standard broth dilution procedure is employed using Ceftazidime $0.25-128 \mu \mathrm{g} / \mathrm{mL}$, Ceftazidime plus clavulanate $0.25 / 4-128 / 4$ $\mu \mathrm{g} / \mathrm{mL}$ and Cefotaxime 0.25-64 $\mu \mathrm{g} / \mathrm{mL}$, Cefotaxime plus clavulanate $0.25 / 4-64 / 4 \mu \mathrm{g} / \mathrm{mL}$ as recommended by CLSI. Following incubation at $37^{\circ} \mathrm{C}$ for 16 hours, phenotypic confirmation is considered as $a \geq 3$ twofold serial dilution decrease in Minimum Inhibitory Concentration (MIC) of either cephalosporin in the presence of clavulanic acid compared to its MIC when tested alone. For confirmatory tests, both cefotaxime and ceftazidime alone and in combination with clavulanate can be used (CLSI, 2015). Swenso et. al., (2004), Hoon et. al., (2009) , EUCAST, (2012) , CLSI, (2015) and Abdelmoktader and Talal, (2019) asserted that Broth Microdilution has been used to detect ESBL production.

\section{Vitek System}

This is an automated microbial identification and antibiotic susceptibility testing that can be used to confirm ESBLs in members of the family Enterobacteriaceae (Dashti et. al., 2006; Shah et. al., 2016). Several other studies (Rupp and Fey, 2003; Spnau et. al., 2006; Putra et. al., 2020) show that Vitek 2 system can be used to detect ESBL Production. This assay relies on card wells containing $1.0 \mathrm{mg} / \mathrm{L}$ of cefepime, or $0.5 \mathrm{mg} / \mathrm{L}$ of cefotaxime or ceftazidime, either alone or in combination with 10 or $4 \mathrm{mg} / \mathrm{L}$ of clavulanate, respectively (Drieux et. al., 2008), following incubation, cards are introduced into the VITEK 2 machine, and for each antibiotic tested, turbidity is measured at regular intervals. An isolate is considered ESBL positive, if a predetermined reduction in growth in wells containing clavulanic acid compared to those without clavulanic acid is observed (Drieux et. al.,2008; Rahman et. al., 2014). Computer algorithms in the vitek system have been used to categorize the beta lactamases present in Gram negative clinical isolates based on the phenotype of susceptibility patterns with various $\beta$-lactam antibiotics. This method is fast, sensitive and specific (Rahman et. al., 2014) ; the method helps to identify Enterobacteriaceae up to genus and species levels (Dashti et. al., 2006) and the susceptibility tests using this method are expressed as MIC values and interpreted as susceptible, intermediate or resistant with reference to a CLSI (Livermore and Brown, 2001; Dashti et. al., 2006; Shah et. al., 2016).

\section{Nordmann/Dortet/Poirel (NDP) test}

This test identifies ESBL producers based on biochemical detection of the hydrolysis of the $\beta$ lactamring of cefotaxime. The procedure of Poirelet. al., (2016) as described by Afolabi et. al., (2017) is as follows. Briefly, $50 \mu$ of a $10 \%$ Triton solution is added into Eppendorf tubes labeled $A$, $\mathrm{B}$, and $\mathrm{C}$ containing $0.5 \mathrm{ml}$ of blood culture and the mixture is vortexed and incubated at room temperature for $5 \mathrm{~min}$ followed by centrifugation at $13000 \mathrm{~g}$ for $2 \mathrm{~min}$. The supernatant is discarded and the pellet is re-suspended in $500 \mu$ distilled water, the bacterial suspension is centrifuged again at $13,000 \mathrm{~g}$ for $2 \mathrm{~min}$, the supernatant is discarded again and the bacterial pellet re suspended in $100 \mu \mathrm{l}$ of $20 \mathrm{mmol} \mathrm{I}^{-1} \mathrm{Tris}-\mathrm{HCl}$ lysis buffer. Ten microliters (10 $\mu \mathrm{l})$ of $40 \mathrm{mgmL}^{-1}$ tazobactam solution is added into tube $\mathrm{C}$; and then $100 \mu \mathrm{l}$ phenol red $(0.5 \%, \mathrm{w} / \mathrm{v})$ into tube $A$ and $100 \mu \mathrm{l}$ phenol red supplemented with cefotaxime $6 \mathrm{mgmL}^{-1}$ into tubes $\mathrm{B}$ and $\mathrm{C}$. The tubes are incubated at $37^{\circ} \mathrm{C}$ for 15 min, change in colour from red to yellow/orange is positive for ESBL production as shown in Figure 5 below (tube B) which contains cefotaxime alone while the tube containing cefotaxime supplemented with tazobactam remained red (unchanged). 


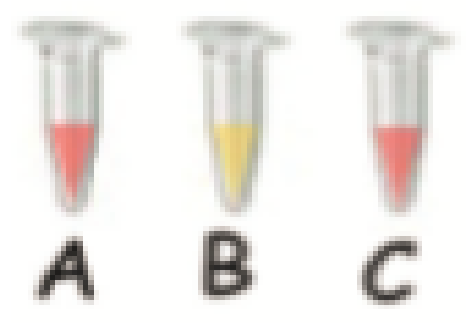

Figure 5: ESBL production exhibited by inoculum in tube B containing cefotaxime alone (Source: Affolabiet. al.,(2017)).

\section{Conclusion}

Infections caused by ESBL- producing bacteria often limits therapeutic options, leading to high disease burden. Therefore, diagnostic laboratories are in need of reliable, cost efficient and less labour intensive methods to use in the detection of ESBL- producing bacteria. Bacteria harbouring ESBL genes are capable of spreading these plasmids to other bacteria via horizontal gene transfer. The public health implications of this are disturbing thus the need to rapidly detect these pathogens in the laboratory. Several techniques of ESBL detection and confirmation have been comprehensively explored in this review and the choice of the testing method depends on the preferences and requirements of the laboratory professionals as well as the availability of the testing material. There is the need for reliable but simple phenotypic tests in the laboratory for the detection of these ARB, which do not require highly skilled personnel, this is in order to ensure a swift response in the management and control of these pathogens. Policy makers in the relevant sectors need to implement strategies to ensure the rapid detection of ESBL- producing bacteria in clinical and environmental samples. 


\begin{tabular}{|c|c|c|c|c|}
\hline $\mathrm{S} /$ & \multicolumn{2}{|c|}{ Methods } & Merits/demerits & References \\
\hline \multirow[t]{3}{*}{1} & \multirow[t]{3}{*}{ E-test } & Merits & sensitive and easy to use & $\begin{array}{l}\text { Rahman et. al., (2014); Nitinet. al., (2014); } \\
\text { Prabha et al.,(2016) }\end{array}$ \\
\hline & & \multirow[t]{2}{*}{ Demerits } & $\begin{array}{l}\text { Difficult to interpret, less sensitive compare to } \\
\text { double-disk test }\end{array}$ & Rahman et. al.,(2014) \\
\hline & & & E-test is expensive & Prabha et. al., (2016); \\
\hline 2 & $\begin{array}{l}\text { Combination } \\
\text { disk test }\end{array}$ & Merits & $\begin{array}{l}\text { This method is better than DDST in the detection } \\
\text { of ESBLs }\end{array}$ & Dejenie Shiferaw Teklu et. al., (2019) \\
\hline \multirow[t]{2}{*}{3} & \multirow[b]{2}{*}{$\begin{array}{l}\text { ESBL Chrom } \\
\text { agar }\end{array}$} & Merits & Rapid, sensitive and specific & \multirow[b]{2}{*}{ Prabha et. al., (2016) } \\
\hline & & Demerits & CHROM agar test is expensive & \\
\hline \multirow[t]{2}{*}{4} & \multirow{2}{*}{$\begin{array}{l}\text { Double Disk } \\
\text { synergy test } \\
\text { (DDST) }\end{array}$} & Merits & Reliable, Easy to use and interpret & \multirow{2}{*}{$\begin{array}{l}\text { Rahman et. al., (2014) } \\
\text { (Jabeen et. al.,(2003) }\end{array}$} \\
\hline & & Demerits & $\begin{array}{l}\text { Distance of disk placement not standardized } \\
\text { DDST was less effective than E-test and CHROM } \\
\text { agar. }\end{array}$ & \\
\hline \multirow[t]{3}{*}{5} & \multirow[t]{3}{*}{$\begin{array}{l}\text { Three } \\
\text { dimensional test }\end{array}$} & Merits & $\begin{array}{l}\text { simultaneous determination of antibiotic } \\
\text { susceptibility and } \beta \text {-lactamase detection (but not } \\
\text { specific for ESBLs) }\end{array}$ & $\begin{array}{l}\text { Singh and Kumar, (2013); Rupp and Fey, } \\
\text { (2003); Nitin et al., (2014) }\end{array}$ \\
\hline & & & Sensitive in ESBL detection & Thomson and sanders, (1992); Bradford, (2001) \\
\hline & & Demerits & Non-specific for ESBLS, labor intensive & Rahman et. al.,(2014) \\
\hline \multirow[t]{2}{*}{6} & \multirow[b]{2}{*}{$\begin{array}{l}\text { Broth micro } \\
\text { dilution }\end{array}$} & Merits & Results can be expressed quantitatively & \multirow{2}{*}{ Alizade et al., (2016) } \\
\hline & & Demerits & labor intensive & \\
\hline \multirow[t]{4}{*}{7} & \multirow[t]{4}{*}{ Vitek system } & \multirow[t]{3}{*}{ Merits } & $\begin{array}{l}\text { automated microbial identification and antibiotic } \\
\text { susceptibility testing }\end{array}$ & Dashti et. al.,(2006); Shah et. al.,(2016) \\
\hline & & & Fast, sensitive, specific & Rahman et. al.,(2014) \\
\hline & & & $\begin{array}{l}\text { Identifies Enterobacteriaceae up to genus and } \\
\text { species level }\end{array}$ & Dashti et. al.,(2006) \\
\hline & & Demerits & Reduced sensitivity & Rahman et. al.,(2014) \\
\hline 8 & & Merits & $\begin{array}{l}\text { Simple, Rapid, cost-effective, sensitive, specific } \\
\text { and reliable }\end{array}$ & $\begin{array}{l}\text { Kumar et. al., (2018), Sadek and Nordmann, } \\
\text { (2019) }\end{array}$ \\
\hline
\end{tabular}




\begin{tabular}{|l|l|l|l|}
$\begin{array}{l}\text { Nordmann/Dort } \\
\text { et/Poirel (NDP) } \\
\text { test }\end{array}$ & Demerits & $\begin{array}{l}\text { The ability of the enzyme to hydrolyze the } \\
\text { substrate, the level of expression of the } \\
\text { corresponding gene and the affinity of the enzyme } \\
\text { for the substrate }\end{array}$ & Sadek et. al., (2019) \\
\hline
\end{tabular}

Table 2: Brief summary of the merits and demerits of the methods used in detection of ESBL 


\section{References}

Abdelmoktader, A. and Talal El Far, A. (2019). Methods of ESBLs Detection in Clinical Microbiol ogy Lab. VirolImmunol J. 3(4): 000222

Abraham E. P. and Chain, E. (1940).An enzyme from bacteria able to destroy penicillin. Rev Infect Dis. 146:837.

Afolabi, D; Sogbo, F; Laleye, G; Orekan, J; Massou, F; Kehinde, A and Anagonou, S (2017). Rapid detection of extended-spectrum beta lactamase-producing Enterobacteriaceae in blood cultures using the ESBL NDP test in Cotonou, Benin. J Med Microbiol 66:884- 887.DOI 10.1099/jmm.0.000509.

Alizade $\mathrm{H}$, Fallah F, Ghanbarpour R, Goudarzi $\mathrm{H}$, Sharifi H, Aflatoonian HR. (2016). Comparison of Disc Diffusion, Broth Microdilution and Modified Hodge Test Susceptibility Testing Of Escherichia coli Isolates to Beta-Lactam Antibiotics.Med. Lab. J. 10 (2):19-24

Al-Muharrmi, Z., Rafay, A., Balkhair, A. and Jabri, A. (2008) Antibiotic combination as empirical therapy for extended spectrum Beta-lactamase. Oman Med J. 23 (2):78- 81.

Anand, N; Ashish K.A; and Madan, M (2016). Detection and Molecular Characterization of ESBLs in E. coli Isolates from a Tertiary Care Hospital in North India with Special Attention to CTX-M-27. British Microbiol Res J 16 (3): 1-7.

Bonnet R. (2004). Growing group of extendedspectrum beta-lactamases: the CTX-M enzymes. Antimicrobagentschemothe 48 (1): 114.

Bradford, P. A. (2001) Extended-spectrum betalactamases in the 21st century: characterization; epidemiology; and detection of this important resistance threat. ClinMicrobiol Rev. 14 (4):933-951.

Carter, M. W., Oakton K. J., Warner, M. \& Livermore, D. M. (2000).Detection of extendedspectrum beta-lactamases in klebsiellae with the Oxoidcombination disk method.J. ClinMicrobiol 38, 4228-32.

Chauhan S; Singh, B M., and Chand, R. D. (2015).Extended spectrum $\beta$-lactamases in urinary isolates of Escherichia coli - prevalence and susceptibility pattern at a tertiary care hospital.Int J Res Med Sci. 3(7):16221626.

Chourasia E, Singh K P; Kher S K (2015). Extended spectrum beta lactamases in clinical isolates of gram-negative bacilli in Ajman, United Arab Emirates.Gulf Med J.4 (1):14-21.

Clinical and Laboratory Standards Institute (2014). Performance Standards for Antimicrobial Susceptibility Testing: Twentyfourth Informational Supplement M100S24Wayne, PA, USA.

Clinical and Laboratory Standards Institute (2015).Performance Standards for Antimicrobial Susceptibility Testing; Twenty-Fifth Informational Supplement M100-S25. Wayne, PA. USA.

Dashti, AA; West, P; Paton, R and Amyes, S.G.B (2006).Characterization of extended spectrum beta lactamase (ESBL) producing Kuwait and UK strains identified by the Vitek system, andsubsequent comparison of the Vitek system with other commercial ESBL-testing system using these strains.

Deshpande, L. M., Jones, R. N., Fritsche, T. R., and Sader, H. S.(2006). Occurrence of plasmidicAmpC type beta-lactamasemediated resistance in Escherichia coli: report from the SENTRY Antimicrobial Surveillance Program (North America, 2004). Inter J Antimicrob Agents 28:578-81.

Drieux, L;Brossier, F. Sougakoff, W and Jarlier, V. (2008). Phenotypic detection of extended- spectrum b-lactamase production in Enterobacteriaceae: review and bench guide. Clin Microbiol and Inf. 14 (1): 90-103.

European Committee on antimicrobial Guidelines for detection of resistance mechanisms and specific resistances of clinical and/or epidemiological importance.

Falodun, O. I; Morakinyo, Y. M and Fagade, O. E. (2018). Determination of Water Quality and Detection of Extended Spectrum BetaLactamase Producing Gram-Negative Bacteria in Selected Rivers Located in Ibadan, Nigeria. Jordan J. Biol. Sci. 11 (1): 107 -112. 
Farzana, R; Shamsuzzaman, S M; Mamun, K Z and Paul S. (2013). Antimicrobial susceptibility pattern of extended spectrum beta lactamase producing gram-negative bacteria isolated from wound and urine in a Tertiary care Hospital, Dhaka city, Bangladesh. Southeast Asian j trop med public health.44 (1): 96-103.

Georgios, M; Egki, T and Effrosyni, S (2014).Phenotypic and Molecular Methods for the Detection of Antibiotic Resistance Mechanisms in Gram Negative Nosocomial Pathogens.Tren Infect Dis140162.Doi.org/10.5772/57582.

Giriyapur R.S, NandihalN..W, Krishna B.V, Patil A.B, Chandrasekhar M.R. Comparison of disc diffusion methods for the detection of extendedspectrum beta lactamaseproducing Enterobacteriaceae.(2011). J Lab Physicians.3:33-6

Gupta, V. (2007).An update on newer $\beta$ lactamases. Review Article. Indian J Med Res. 126 (5): 417-427.

Hassan H and Abdalhamid B (2014).Molecular characterization of extended-spectrum beta- lactamase producing Enterobacteriaceae in a Saudi Arabian tertiary hospital.J Infect DevCtries8 (3): 282-288.

Hoon, S, J; Song, W;Kim, J; Kim, H and Man, K, L. (2009). Broth Microdilution Method To Detect Extended-Spectrum -Lactamases and AmpC BLactamases in Enterobacteriaceae Isolates by Use of Clavulanic Acid and Boronic Acid as Inhibitors. J. ClinMicrobio, 47 (11): 3409-3412.

Hornsey M, Phee L, Woodford N, Turton J, Meunier D, Thomas C, Wareham DW (2013) Evaluation of three selective chromogenic media, CHROMagar ESBL, CHROMagar CTX-M and CHROMagar KPC, for the detection of Klebsiellapneumoniae producing OXA-48 Carbapenemase. J ClinPathol 66: 348-350.

Jabeen, K., Zafar, A., Hasan, R. (2003). Comparison of double disc and combined disc method for the detection of extended spectrum beta lactamases in enterobacteriaceae.J Pak Med Assoc, 53(11), 534-536.

Kang, C. I., Kim, S. H., Park, W. B. Lee, K. D., Kim, H. B., Kim, E. C., Oh, M. D. andChoe, K. W.
(2004). Bloodstream infections due to extendedspectrum beta-lactamase-producing Escherichia coli andKlebsiellapneumoniae: Risk factors for mortality and treatment outcome, with special emphasis on antimicrobial therapy. Antimicrob Agents Chemothe.48 (12):4574-4581.

Kaviyarasan, G.,Rajamanikandan, K.C.P., Sabarimuthu, M., Ramya, S., and Arvind, P. D. (2018). Antimicrobial susceptibility and detection methods for the extended-spectrum beta lactamases producing enterobacteriaceae from clinical samples.Asian J Pharm Clin Res, 11 (5):139-142.

Khosravi, A D; Hoveizavi, H; Mehdinejad, M (2013).Prevalenceof

Klebsiellapneumoniae Encoding Genes for CtxM-1, Tem-1 and Shv-1 Extended-Spectrum Beta Lactamases (ESBL) Enzymes in Clinical Specimens.Jundishapur J Microbiol. 6 (10): e8256.

Kumar S, Bandyopadhyay M, Kumari P, Sengupta A, Das S, Bandyopadhyay $M$, Kumar $P$ M; Chatterjee, M (2018). Extended-spectrum beta lactamase detection by extended-spectrum betalactamase-Nordmann/ Dortet/Poirel test: Where time is the essence. J Med Soc. 32 (2):140-143.

Lachmayr, K.L., Kerkhof, L. J., DiRienzo, A.G., Cavanaugh, C.M. and Ford, T.E. (2009). Quantifying Nonspecific TEM Beta Lactamase (blaTEM) Genes in a Wastewater Stream.App EnvMicrobiol. 75(1): 203-204.

Linscott A. J and Brown W. J (2005). Evaluation of Four Commercially Extended Spectrum Beta Lactamase Phenotypic Confirmation Tests.JClinMicrobiol. 43 (3):10811085.

Livermorea, D.M and Derek Brown, D. F.J., (2001). Detection of Beta-lactamasemediated resistance.J. Antimicrob.Chemother. 48, Suppl. S1, 59-64.

Lohani, B; Thapa, M; Sharma, L; Adhikari, H; Anil K. S; Arun, B. K; Ranga B. B and Aryal, M (2019). Predominance of CTX-M Type Extended Spectrum Beta Lactamase (ESBL) Producers among clinical isolates of Enterobacteriaceae in a Tertiary Care Hospital, Kathmandu, Nepal.The Open Microbiol J. 13, 28-33. 
Mahmoud M. T; Abdel-Nasser, A. E; and Mohamed A H (2016). PCR-Based Molecular Detection of ESBLs Encoding Genes blaTEM, blaCTX-M and blaSHV among MDR Escherichiacoli Isolates from Diarrhoea Stool Cultures in Cairo, Egypt. Int. J Res StudMicrobiol Biotech (IJRSMB) 2 (3): 7-14.

Mangaiyarkarasi, T; Senthil P. D; Ragunathan, L; Baskaran K, Hemalatha G, Rayapu, V and Anand S I (2013). Comparison of double disc synergy test and phenotypic confirmatory disc diffusion test for detection of esbl production and their antimicrobial resistance pattern.Int. J ApplBiol Pharm Techn 4 (2): 35-39.

Maria, C, D. (2013) Beta-lactamases in Enterobacteriaceae in broilers.GVOdrukkers and vormgevers B. Ponsen\&Looijen, Wageningen.

Naseer, U., Natas, O.B, Haldorsen B.C, Bue B, Grundt, H., Walsh T.R(2007). Nosocomial outbreak of CTX-M-15-producing $E$. coli in Norway.APMIS 115 (2):120-126.

Nitin, I G; Sharma Sachin, ChaudharyPravin Kumar, Payal Nikhil, YadavSuneet. (2014). Different phenotypic methods for detection of ESBL production in bacteria: A review. J Pharm SciInnov.3 (3): 197-198.

Nordmann, P; Dortet, L and Poirel, L (2012).Rapid Detection of Extended-SpectrumBetaLactamase-Producing Enterobacteriaceae.J. ClinMicrobiol 50(9): 30163022.

Paterson, D. L. and Bonomo, R. A. (2005). Extended-Spectrum beta lactamases: A clinical update. Clin.Microbiol Rev 18 (4): 65786.

Peter-Getzlaff, S. (2011). Detection of AmpC beta lactamase in Escherichiacoli: comparison of three phenotypic confirmation assays and genetic analysis. J ClinMicrobiol 49(8): 2924-2932.

Pitout, J. D., Le, P. G., Moore, K. L., Church, D. L. and Gregson, D. B.(2010). Detection of AmpC beta-lactamases in Escherichia coli, Klebsiella spp., Salmonella spp. and Proteus mirabilis in a regional clinical microbiology laboratory.ClinMicrobiol Infect. 16:165-70.

Pitout, J. D. and Laupland, K.B. (2008). Extende $\mathrm{d}$-spectrum beta lactamase producing
Enterobacteriaceae: an emerging public health concern. The Lancet Infect Dis 8(3): 159-166.

Poirel L, Fernandez J, Nordmann P. (2016). Comparison of three biochemical tests for rapid detection of extended-spectrum beta lactamaseproducing Enterobacteriaceae.J ClinMicrobiol54: 423-427.

Prabha, R; Joshy M. E and Swapna, M (2016). Phenotypic detection of Extended Spectrum Beta- Lactamase producing uropathogens using DDST, PCT, Chrom agar and E-test A comparative study. Int. J. Curr. Microbiol.App. Sci5(4): 565-577.

Prestinaci F, Pezzotti P, Pantosti A. (2015). Antimicrobial resistance: A global multifaceted phenomenon. Pathog Glob Health 109: 309-318.

Putra, A.R. Effendi, M.H. Koesdarto, S. Suwarno, S. Tyasningsih, $W$ and Estoepangestie, A.T. (2020). Detection of the extended spectrum $\beta$ lactamase produced by Escherichia coli from dairy cows by using the Vitek-2 method in Tulungagung regency, Indonesia. IraqiJ. ofVetSci 34 (1): 203-207

Rahman, M; Rahman, M M; Akhter J, W (2014). Clinical Laboratory and Molecular Detection of Extended Spectrum beta lactamases: A Review Update. Bangladesh J Infect Dis $1 \quad$ (1):12-17.

Rawat, D and Nair, D. (2010). Extendedspectrum beta lactamases in gram negative bacteria. J. Glob Infect Dis 2 (3): 263-274.

Revathi G. (1997). Detection of extended spectrum $\beta$ lactamases using E-test ESBL strip. Indian J Med Microbiol 15(2): 69-71.

Rupp Mark E and Fey Paul D. Extended Spectrum $\beta$-Lactamase

(ESBL)-Producing Enterobacteriaceae Considerations for Diagnosis, Prevention and Drug Treatment. Drugs 2003; 63(4): 353-365.

Sadek, M; Poireel, $\mathrm{L}$ and Nordmann $\mathrm{P}$ (2019).Novel biochemical and reliable technique for the rapid detection of extended spectrum $\beta$ lactamase-producing Enterobacterales; the rapid ESBL NP test.Pediatric Dimensions. 4 1-5

Samra, Z; Heifetz, M.Talmor, J. Bain, E. and Bahar, J. (1998). Evaluation of use of a New Chromogenic Agar in Detection of Urinary Tract 
Pathogens. J Clin Microbiol,36 (4): $\quad$ 990994

Shah K, Shrimali G, Mulla S. (2016).Comparison of Double Disc Diffusion Method and Vitek 2 Compact System to Screen the ESBL Producers in Intensive Care Unit in Hospital.NtIJ Community Med 7(9):789-791.

Shaikh, S; Fatima, J; Shakil, S; Mohd, S; Rizvi, D. and Amjad, M. K. (2015). Antibiotic resistance and extended spectrum beta-lactamases: Types, epidemiology and treatment.Saudi J. BiolSci 22(1): 90-101.

Shiferaw, D.T., Melese H.L., Kirubel, E., Abebe, A., N., Surafel, F., Tesfa, A., Tesfaye, L.B., Hi wot, K.W., Yonas, M., Dawit, A., Abera, A., Amet e, M., Rajiha, A., Etsehiwot, A., Mulushewa, G ., Degefu, B., Elias, S., Negga, A., Yohannis, Y., Estifanos, T., Semira, E.,Zeleke, A.,Eyasu, T., and Kassu, D. T. (2019). "Comparison of Double Disk Synergy Test and Combination Disk Test Methods for the Detection of Extended- Spectrum Beta-Lactamase Production among Enterobacteriaceae'. EC Microbiology 15.6 (2019): 411-420.

Singh RK, Manoj Kumar. A (2003).Simplified method of Three Dimensional Technique for the Detection of AmpC Beta-Lactamases.Arc of Clinmicrobiol 4(3.1).

Singh, R MandLokhendro S H (2014).Comparative evaluation of six phenotypic methods for detecting extendedspectrum betalactamase-producing Enterobacteriaceae. J Infect DevCtries 8(4):408-415.

Spanu, T., Sanguinetti, M., Tumbarello, M., D'Inzeo, T., Fiori, B., Posteraro, B., Santangelo, R.,Cauda, R. and Fadda, G. (2006). Evaluation of the New VITEK 2 Extended-Spectrum BetaLactamase (ESBL) Test for Rapid Detection of ESBL Production in Enterobacteriaceae Isolates. J. ClinMicrobiol44 (9): 3257-3262.

Swenson, JM George E. Killgore, and Fred C. Tenover (2004). Antimicrobial Susceptibility Testing of Acinetobacter spp. by NCCLS Broth Microdilution and Disk Diffusion Methods.J. ClinMicrobiol 42 (11): 5102-5108

Thomson, K.S., Sanders, C.C.(1992). Detection of ESBLs in members of the family Enterobacteriaceae. Comparison of the double di sc and three-dimensional test. Antimicrob Agents Chemothe 36:1877-1882.

Turner,P.J. (2005). Extended Spectrum Beta lact amases. Clin Infect Dis 41:(4): 273-275.

Uyanga, FZ; Ekundayo, E. O. Nwankwo, E. O. and Inimfon, A. I. (2019). Evaluation of CHROMagar ESBL and Double Disk Synergy Test (DDST) for Screening of Extended Spectrum Beta-lactamase Producing Uropathogens in South-South Nigeria. Adv Microbiol. 17(4): 1-11.

Vercauteren, E., Descheemaeker, P., Ieven, M., Sanders, C.C. and Goossens, H.(1997).Comparis on of Screening Methods for Detection of Extended Spectrum Beta Lactamases and Their Prevalence among Blood Isolates of Escherichia coliand Klebsiella spp. in a Belgian Teaching Hospital. J. Clin Microbial35 (9): 2191-2197

World Health Organization.(2014). Antimicrobial Resistance Global Report on Surveillance. Geneva

Ximin, Z. and Jun, L. (2013).Beta-lactamase induction and cell wall metabolism in Gramnegative bacteria. Review article. Front Microbiol $.4(128)$

Yarima, A., Salihu, M. K and Gurama, A. G (2019). Phenotypic detection of extended spectrum beta lactamases in Escherichia coli and Klebsiellapneumoniae isolated from patients at the Federal Teaching Hospital Gombe, Gombe State, Nigeria. FUDMA J. Sci(FJS) 3 (4): 434-439. 